\title{
Function and Types: Code Mixing and Code Switching in Leti (Types and Frequency)
}

\author{
Renhard Saupia \\ \{renhard_saupia@suluh.org\} \\ Yayasan Suluh Insan Lestari Jakarta, Indonesia
}

\begin{abstract}
Switching and mixing become part of linguistic diversity in multilingual country. Experts believe that switching and mixing between language purposed to emphasize statement, quote idea, strengthening command or request and so forth [1]. This study tries to investigate the types of code switching and mixing that used in Leti and more is to see the frequency of the usability of code switching and mixing in one single speech. The data is analyzed qualitatively to see the types and statistically to discover the frequency of usability. The finding shows that there are two types of switching that appeared, namely; tag switching and syntactical inter sentential as shown in the phrase 'Yance kamaringitu!..., and nanti bangun ka? Tidur lai?. Moreover, there are two types of mixing that discovered they are insertion and alternation as in 'Karna rie rkenale, apalagi rpatromnena rie he nwene...', wakampungo'. The frequency of usability also showed that tag switching highly used in this speech with numbers of lexical is 137 words and the frequency of usability is 0,1 , followed by the syntactical-inter-sentential switching 77 words and the frequency is 0,05 , the numbers of insertion is 49 words with 0,04 in its frequency and alternation with 14 words and 0,01 for its frequency.
\end{abstract}

Keywords - code switching, code mixing, bilingualism

\section{Introduction}

Code switching and code switching is common phenomena in Linguistics study toward society. This phenomenon could happen in any language around the world. The users of a language switch or mix language fundamentally are to emphasize message, reach inexpressible lexical in their native language or to fulfil the needs of society and globalization. There are about eight reasons why the users of particular language switch or mix language[1]. He claimed that users switch and mix a code likely to: talk of particular topic, quote somebody else, emphasize, make interjection, repeat in order to clarify, express group identity, soften or strengthen a request or a command and meet lexical need of a language. It can be assumed from Hoffman's that switching or mixing among languages happen to stabilize the need of speech community.Code switching is defined as the use of more than one language, variety, or style by speaker within an utterance or discourse or between different interlocutor or situation [2]. It means switching the code occurs when there are more than one language communications 
among the users. The speaker was his or her ability in another language, style, dialect or anything it served by the speaker depends on the addresses in different occasions.

[2]A sociolinguist also proposed three types code switching. (a) Tag switching, is a simply insertion of tag in one language in on utterance which is entirely in the other language. (b) Inter sentential switching, involvers a significant amount of syntactic complexity and conformity to the rules of both languages. Therefore, speakers performing this kind of switching are usually fairly proficient in the participating languages. (c) Inter sentential switching refers to the same clause or sentence which then contains elements of both languages.

Code mixing is the change of one language to another within the same utterance or in the same oral or written text. It is a common phenomenon in multilingual society. [3] Types of code mixing is divided into three main types: (a) Insertion of words and phrase which happened where there is an insertion to constrain in term of the structural properties some base in matrix structure: For example: 'nanti siang jadi meeting dimana?'. (b) Alternation refers to mixing in terms of capability or equivalence of language involve at switch point. Here is one of the examples: 'Ngeprint berapa lembar?'. (c) Congruent lexicalization happened where there is mixing of style, shifting and dialect or standard variation rather than bilingual language use proper. For example: "hai, how are? I'am Sam. Senang bertemu dengan anda. Nice to meet you". In order to see the switching and mixing phenomena of Leti, the writer is attracted to find out the types of mixing and switching in Leti, also to discover the frequency in a single speech of a native speaker of Leti.

Furthermore, the scopes of this study are to discover the types of code switching and mixing in a single speech, and see their frequency of usability. For answering the purposes of this investigation, two research questions are designed:

What are the types of code switching and mixing in Leti?

How often Code Switching and Code-mixing are used?

\section{Methods}

The data was taken through recording. In fact, the speaker didn't realize that he is being recorded. [4] suggested researcher to obtain consent form of the speaker to avoid conflict. This consent form could be written form or oral through diplomacy. In order to fulfil the need of this research, the researcher has contacted the speaker personally to possess the consent form in order to avoiding human rights issue in the future. As has explained before that the data is transformed into textual version. In order to discover the findings, the researcher transcribe the audio files using ELAN and export it into Microsoft Words [5]. However, to answer question for this research takes a qualitative descriptive study that produces data in the form of words written that recorded through a speech or utterance. [6] Qualitative data which usually involves recorded spoken data that is transcribed to textual form as well as written notes and documents of various sorts. Qualitative method is used to answer first research question (Q1). While the second research question (Q2) is analyzed used statistical analysis. The formula that used in answering it can be seen as follow:

\begin{tabular}{|c|c|}
\hline Relative Frequency & absolute frequency \\
\hline of Usability & $\sum$ data \\
\hline
\end{tabular}




\section{Result and Discussion}

The writer found that there are two types of code switching (CS) that appeared, namely; the tag switching, and syntactical Inter sentential. As has defined previously that tag switching is a simply insertion in a language which entirely in other language.

Table 1. Tag Switching

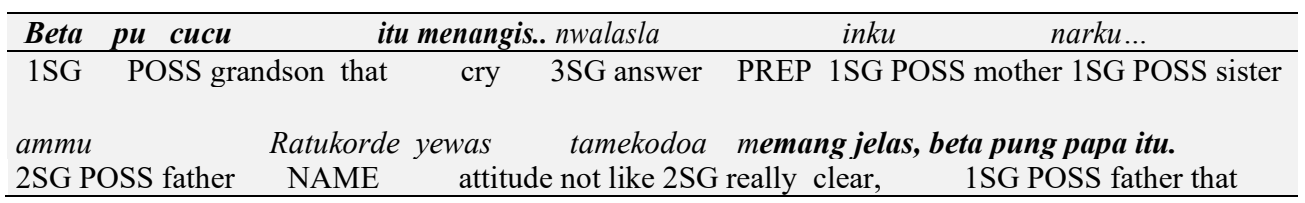

The table above shows that the used of Tag Switching is unpredictable and move without any boundary of language. This kind switching sometimes show up in dependent clause as in the clause 'kamaring itu', 'beta pu cucu itu menangis', and others are unchangeable but ties into the native language. Practically, the purpose the tag switching here is to emphasize the message to hearer.

Table 2. Syntactical Inter sentential Switching

\begin{tabular}{lcccc}
\hline Koi neram & denanti & Bangun ka? & Tidur lai? \\
\hline Baby 3SG wake up & ART later & wake up INTEROGATIVE MARKER sleep again \\
Nlawa lerne & la & perkare masallede, seng ada sopi & me.. \\
3SG go day & PREP problem problem PREP not is & alcohol ART \\
\hline
\end{tabular}

Based on ${ }^{[2]}$ this type of switching refers to the switching that occurs inside the same clause or sentence then contains elements of both languages. It clearly be seen that those two sentences have syntactical switching and its phonologically match into Leti. For example, in the 'perkare masalle' it supposed to be like 'perkara masalah' but it is not. It falls in to the sound flow and movement of Leti. Furthermore, it can be said that the switching of language can adapt with the main language to create unquestionable meaning and unambiguous meaning.

This study discovered two types of code mixing that the speaker use. The first is insertion which is refer to an inserting of new words to structural properties of a language. However, words that used to insert or mix into the main language lexically exist in the language ${ }^{[2]}$. Insertion can be seen on the table below:

Table 3. Insertion

\begin{tabular}{lcccl}
\hline Atau awemnu juga, nliwar & niwatku de & cukup & \\
Or 1SG drink also 3SG hit & 3SG POSS lips ART & enough & \\
Kira-kira lira hede lira & yatcate ... & & \\
About voice that voice & bad & & \\
Karna rie rkenale, & apalagi rpatromnena & rie he nwene... \\
Because people 3PL know, & moreover 3PL meet & people that 3SG said... \\
\hline
\end{tabular}

The insertion such as, 'juga, cukup, kira-kira, apalagi' is taken directly. However, those words fundamentally existed in Leti. For example, 'kira-kira', Leti has it in 
'awarore/ombwarore'.The other type of Mixing that found in Leti is called Alternation. It defined to how speakers of a language constraint on mixing in terms of capability or equivalence of the language involve at the switch point ${ }^{[2]}$.

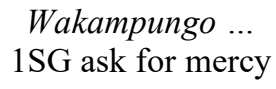

Nsaluut...

3SG proud

Switching that existed in this speech syntactically and morphologically acceptable into the sentence pattern of Leti. For example, the word 'rkenale' is a sentence formation of Leti ' $r$ [Subject] + kenale [Verb] which is the basic sentence pattern of Leti. However, the verb 'kenal' is from Indonesian and being matched to create Leti's sentence structure. As mentioned by ${ }^{[2]}$ that all of these words are constrained or forced by the user to meet the equality with high-language. It can be said that Alternation of mixing also have the potential to cross the sentence structure of a language morpho-syntactically.

Frequency of Usability

The frequency of the usability in this study mainly aimed to see how many times the switching and mixing are show up in the speech of the participant in lexical level. The details of the frequency of code switching and mixing can be count used mathematical formulation of frequency as follow:

Frequency of Usability of Code Switching and Mixing

The total of words that showed up are 1375. Tag switching took 137, syntactical inter sentential have 77 words, the insertion of mixing has 49 words, and the alternation has 14 words. The result of the frequency can be seen on the table below:

\begin{tabular}{|c|c|c|c|}
\hline & $\begin{array}{c}\text { Relative Frequency } \\
\text { of Usability }\end{array}$ & $\begin{array}{l}\text { absolute } \\
\Sigma \text { data }\end{array}$ & frequency \\
\hline Tag Switching & $\begin{array}{c}\text { Syntactical Inter } \\
\text { Sentential }\end{array}$ & Insertion & Alternation \\
\hline $\begin{array}{r}\text { Freq. } T S= \\
137 / 1375=0,1\end{array}$ & $\begin{array}{l}\text { Freq. } S S= \\
\quad 77 / 1375=\mathbf{0 , 0 5}\end{array}$ & $\begin{array}{r}\text { Freq. Ins }= \\
49 / 1375=0,04\end{array}$ & $\begin{array}{c}\text { Freq. Alt }= \\
14 / 1375=0,01\end{array}$ \\
\hline
\end{tabular}

\section{Conclusion}

Based on this research, the writer concluded that Tag Switching could be switched between Indonesian and Leti without disrupting the meaning. Syntactical inter sentential of Indonesian is adaptable to Leti. Insertion of mixing of Indonesia has potential to change main lexical of Leti. Alternation of mixing of Indonesian has highly accepted to form sentence in Leti without broke the basic formation of the sentence structure and pattern of Leti morpho-syntactically. 


\section{References}

[1] C. Hoffman, An Introduction to Bilingualism. 1991

[2] S. Romaine, Language in Society. Oxford University Press, 2000.

[3] P. Muysken, Bilingual Speech: A Typology of Code-Mixing. The Edinburgh Building: Cambridge University Press, 2000.

[4] G. Holton, "Relatively Ethical: A Comparison of Linguistic Research Paradigms in Alaska and Indonesia," Language Documentation \& Conservation, vol. 3, no. 2, pp. 161-75, 2009.

[5] Jukes, Anthony, and Yanti, ELAN: Transcribing Audio and Video on an Endangered Langauges." presented at the Language Documentation on Minority Language. Artha Wacana Christian University, 2016.

[6] Z. Dornyei, Research Methods in Applied Linguistics Quantitative, Qualitative, and Mixed Methodologies. 2007. 